\title{
Research on the Relationship Between the Costume Etiquette System and the Development of Social Politics and Economics
}

\author{
$\operatorname{Lin} \operatorname{Lin}^{1, *}$ \\ ${ }^{1}$ Tianjin Arts and Crafts Vocational College, Tianjin, China \\ *Corresponding author. Email: 11781899@qq.com
}

\begin{abstract}
Costume culture and etiquette system are closely related to social, political and economic development. Based on the characteristics of Western costumes and the ancient and modern dress etiquette culture, this paper analyzes in detail the development law of dress etiquette system and its relationship with the development of society, economy and culture. Throughout the ancient Chinese culture, costume has become an indispensable form in Chinese history. Contemporary dress etiquette is changing with the development of social civilization, playing an irreplaceable important role. This paper combines theory with practice, summarizes rules and researches, and makes the demonstration through a large number of examples and data analyses. Also, it analyzes the development direction of contemporary costume culture and etiquette, and extends the research results to the application field of costume art. As a kind of culture, clothing has a long history. Nowadays, clothing has more social attributes and is an important part of people's social life. The significance of clothing also changes dramatically with the changes of the era. Taking costume as a mirror, we can explore the development of social politics and economy. Similarly, social politics and economy also restrict and influence the change of people's ideas and costumes.
\end{abstract}

Keywords: dress etiquette, clothing art, dress culture

\section{INTRODUCTION}

The dress etiquette has a change and innovation for thousands of years, which are closely related to the political and economic development of society. In today's harmonious society, dress plays an irreplaceable role.

Due to the constraints of historical traditions, customs, religious beliefs and the trend of the times, dress etiquette form is not only recognized by people, but also observed by people, and it becomes the integration of all kinds of codes and norms of conduct that meet the requirements of communication for a harmonious relationship. Briefly, dress etiquette is a code and norms of conduct that people should abide by in social activities.

As a kind of culture, dress runs through people's social communication, through which we can judge a person's identity, status, occupation, cultivation and even value orientation. Dress can also reflect the personality and aesthetic pursuit and we should follow some etiquette norms of the Public Opinion on Dress and combine with the political construction of current harmonious society to form a guide for our dress. Dress

etiquette changes with the development of social civilization, and its relationship with social politics and economy is also worth further study and discussion.

\section{EMBODIMENT OF DRESS ETIQUETTE IN SOCIAL POLITICS}

In contemporary dress etiquette, Chinese dress has undergone major changes. The strict hierarchical dress system which dominated China for thousands of years has been abolished and replaced by a loose, free, individual, and integrated dress system.

Dress etiquette plays a role in regulating and maintaining a certain order in the relationship between society, groups and individuals. As we are now familiar with the dress code to wear a suit or the traditional dress of your own country in formal diplomatic occasions, the dress etiquette has certain binding force in today's world.

Under the collision of Eastern and Western cultures, suits have long been known to Chinese people. Initially, most of the suits were imported. During the Republic of China period in 1912, it was clarified as a formal dress. The suit quickly became common clothing in the social 
etiquette of the upper class and an important ceremonial dress in Chinese political life. Basically, all the military and political dignitaries of the Republic of China and the aristocrats of the Qing Dynasty wore suits. This is inseparable from the development of social politics in the Republic of China and the exchange of Eastern and Western cultures. A very important reason why the suit lasts forever has a deep cultural connotation. It does have a solemn, stable, elegant and chic style in wearing a suit. The suit culture is often regarded as "literate, educated, gentlemanly and authoritative". The main characteristics of the suit are its straightforward appearance, smooth lines and comfortable wearing. If it is fitted with a tie or bow tie, it will look more elegant and simple. But wearing a suit also has strict etiquette requirements, such as the "three-color principle" in matching, that is, the suit can't exceed three colors on the whole body. "Three laws", when wearing a suit, belt, shoes, and briefcase should be the same color, generally black.

Corresponding to the men's suit is the lady's cheongsam. Cheongsam is the most popular women's clothing and full dress in the period of the Republic of China. Cheongsam represents the typical beauty of Chinese women and is the perfect combination of classical and era. The cheongsam in the Republic of China period has made elaborate changes in style, structure and decoration. Improved cheongsam is widely popular as a social dress. The old-school people accept it because it has the meaning of traditional Chinese culture; the new-school people prefer its fashion sense similar to Western-style clothing. Cheongsam has a very important role in shaping a lady's body, and there are many etiquette rules for wearing cheongsam. So now in many formal business occasions and social occasions, ladies still like to wear cheongsam to show elegant style. But there are also some irregular dresses that weaken the influence of cheongsam in national clothes.

After the founding of New China, the clothing of this period showed the characteristics of simplicity and life oriented. The classic dresses which adapted to political development are Chinese tunic suit, Lenin suit, etc. Chinese tunic suit has the characteristics of restraint and implicitness of the Chinese nation.

After China's reform and opening up, the leaders took the lead in wearing suits, which indirectly established the status of suits in the clothing field of New China. With the development of social politics and the increase of international exchanges, suits have once again become the most important clothing in Chinese business etiquette activities. People from all walks of life take suits as regular dresses and it appeared in various ceremonies and social occasions. In the 1980s, women also put on suits, suit skirts and suit trousers also became a match of day dresses.
Exotic dress etiquette has a huge influence on Chinese costumes. Similarly, Chinese traditional dress etiquette also plays a decisive role in the world's dress culture. With the inheritance and rejuvenation of traditional culture, Tang suits are also blowing Chinese style all over the world. We often see some foreigners wearing Tang and Han costumes and learning traditional Chinese culture. The influence of traditional costume culture etiquette has become increasingly prominent in the world. We must pay attention to this cultural inheritance and carry forward the national dress etiquette.

It can be seen that the dress etiquette system and the development of social politics are inseparable. Social and political development determines the dress etiquette system. Also the etiquette system always adapts to political development. Especially in the contemporary era, the multi-polarization and internationalization of political development have demonstrated the characteristics of openness and inclusiveness. The role of stars and social celebrities as popular leaders is even more influential. Their dressings in front of various medias, and even the clothes they wear in daily life directly affect the consumption direction of Chinese dress. The dress of high-end people such as celebrities, politicians, and wealthy people has basically been synchronized with world fashion. The dress system has also evolved from a high degree of unity to individualization and internationalization.

But we must also notice another trend that today's political development in China has begun to return to exploring, inherit and innovate the connotation and essence of traditional Chinese culture, instead of following the political trend of the West and deny ourselves. Shown in dress, it began to focus on "Chinese design" and "Made in China."

Dress is a culture that runs through people's social interactions. We can judge a person's identity, status, occupation, cultivation, and even value orientation through dress. Dress can also reflect the personality and aesthetic pursuit. The dress etiquette system is an important part in the construction of a harmonious society. It regulates people's dressing behavior, guides the aesthetics of costumes, and promotes good moral customs, good interpersonal relationships and orderly social order. It is also closely related to daily life. Our country has a history of 5,000 years and is known as the "kingdom of dress". Its dress etiquette is also in a process of advancing with the times, constantly developing and perfecting, and moving towards harmony.

In short, the changes and reforms of dress etiquette over thousands of years are inextricably linked to the political development of society. In today's harmonious society, it is playing an irreplaceable and important role. 


\section{DRESS ETIQUETTE SYSTEM AND SOCIAL AND ECONOMIC DEVELOPMENT}

In the 21st century, human civilization has developed to a very high level. The rapid development of science and technology and the rapid development of material civilization have made people's lives reach unprecedented levels. Dress etiquette also realizes the leap frog development under the impetus of the economy.

\section{A. Looking at dress etiquette and economic development from a historical perspective}

Social and economic development is the material basis and decisive factor for the prosperity of dress etiquette. The level of dress development cannot exceed the level of social material wealth production capacity.

"The economic foundation determines the superstructure", and dress can reflect the most special power in the superstructure. The ruling classes of all dynasties have formulated corresponding dress regulations in the rules of state governance, but due to the different levels of economic development, the dress etiquette system is slightly different. The general situation is that dynasties with better economic development, then the development of dress etiquette is better as well. In short, dress is a mirror, from which we can clearly discover the marks of social progress and historical development.

The aesthetic standards of the ancient dress etiquette culture were determined by the highest rulers of ancient times according to their own political needs based on their own aesthetic standards. The people could only obey, and the development of dress was based on the economic foundation of the time. The emperors, nobles, civil and military officials and their families belonged to a group of people who distinguished themselves by their prominent dresses at that time, and their dress etiquette clearly reflected the level of economic development and political openness at that time. Therefore, from a certain period of time, "the history of dress development is centered on aristocratic dress." The way we learn the dress etiquette culture of a historical dynasty is often judged by the economic development of the society at that time.

Taking the Tang Dynasty for example, in Tang period, no matter political, economic, cultural, or ideological fields it all reached their heyday in feudal society. The unification of the country, the prosperity of the economy and culture, and the development of dress presented an unprecedented splendid scene in both materials and styles. From the perspective of the economic strength of the entire country, the Tang Dynasty was quite rich and powerful. It was one of the few civilized and prosperous empires in the world at that time. This allowed the rulers of the Tang Dynasty to maintain a positive attitude towards opening up to the outside world. The gorgeousness, nobleness, richness, extravagance, and foreign admiration of the costumes all benefited from the strong economic strength. The Silk Road opened up trade and commerce. The first thing it brought to people was the abundance of material life. This also greatly stimulated the consumer desire of the people in Tang Dynasty. Among them, apparel consumption is a prominent aspect. Economically prosperous made them be able to pursue the apparel consumption that is almost extravagant and admirable to foreign world. The emperor and loyal family pay attention to the dress etiquette, the gentry and rich people followed the trend, and the people will regard it as their ideal of dress.

Due to the prosperity of the country, economic prosperity, and society openness, the personalization of dress in the Tang Dynasty has been greatly publicized. Women can wear low-cut blouses or narrow-sleeved men's clothing, which became a unique symbol of that era; the prevalence of "Hu dress" in the Tang Dynasty also stems from this, which is also rare in Chinese history. It can be said that the clothing of the Tang Dynasty was the clothing that best meets the needs of humanity among the feudal dynasties, and its dressing concepts and ideas are very close to that of modern people.

The "prosperous world" embodied in the dress and economy of the Tang Dynasty was only a magnificent chapter in the long feudal society. Most of the time, the influence of the feudal ritual system on dress was more specific and strict. Every Chinese dynasty all applies strictly ritual bond on dress, the hierarchy of dress is very significant, and to a certain extent, it realizes "notify the people with high or low levels only from the appearance." This strict restraint of social etiquette gave rise to the concept of esteem and inferiority. Even if the common people are very rich, they can only differ in the materials and workmanship of the clothing, and must not exceed the etiquette system. This is how the etiquette maintains privileges and prevents them from overflowing. Political power is above the economy, directly interfering with the dress of all classes from the consumption field, and the distribution of clothing is determined by the distribution of power. The supereconomics forcibly penetrate in all aspects of social life.

\section{B. Western dress etiquette and economic development}

Developed capitalist countries in Europe and the United States always have a say in fashion dress. Because of their powerful economy, their dress etiquette is also better developed. Nowadays, the world's annual release of fashion styles and colors is dominated by these countries. A country's economic development will definitely affect its cultural 
development, which also includes fashion trends. Young people are the main carriers of fashion clothing. They are most concerned about fashion. Their dress can directly reflect the economic situation of society, and their dress taste and dress etiquette will become the most mainstream direction of society. When the social and economic development is good, the uniform national spirit is dominant, and the personalized clothing language is weak. When the economic development is not optimistic, young people's fashion clothing may contain some negative information of rebellion, such as exaggerated colors, special models, etc. Generally speaking, the clothing of young people can be regarded as the vane of social development in a certain sense. They will very sensitively capture the social development status and economic situation.

The 1960s in Europe and America was a period of "rebellion". Hippie culture originated in the United States and quickly spread to Europe. The hippie culture mainly promoted peace, anti-war, anti-government control of human rights and opposition to the moneycentered value of the middle-class at that time. The hippies dreamed of a free life without classes, which was contrary to the mainstream society at that time. They don't wear suits or ties, traditional dress taboos are challenged, jeans, miniskirts, flared pants, overalls, and streetwear for young people are popular all over the Western countries.

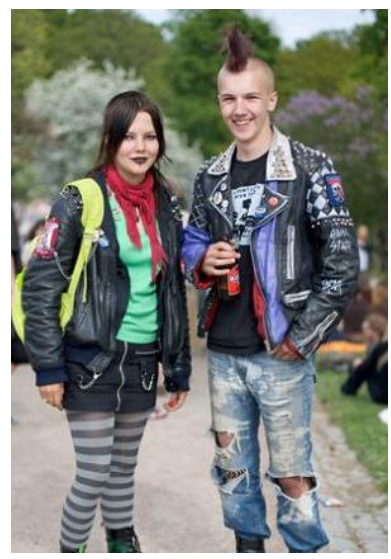

Fig. 1. "Punk" style clothing.

The energy crisis occurred in the West in the 1970s. The direct impact of the energy crisis is: clothing puts functional factors in an important position, and the overall trend of women's clothing is toward conservative. On the one hand, people have changed the values of high consumption, and in order to reduce cost, the clothing industry has widely adopted linear cutting methods. On the other hand, fashion designers under the post-modern trend of thought turned fashion design into an experiment to break the tradition. Clothes with holes, exaggerated and ugly decoration, and incomprehensible shapes are everywhere on high fashion shows. The appearance of "punk" clothing in society ("Fig. 1") is a rebellious style. It is characterized by brightly colored hair and simple clothing with metal, reflecting the atmosphere of the street, such as women wearing men's clothing and worn jeans.

In the 1980s, the Western economy improved, and the affluent life caused people to admire famous brands, worship high consumption, and raise the style of yuppies. Yuppies have a superior social background, such as a high social status, generous salary and so on. They are not necessarily young, but their pursuit of luxury goods and high-end enjoyment is still enthusiastic. Yuppies are well-dressed and they reveal the good living conditions they have from every detail. Splicing an oval leather patch on the elbows of expensive suits was once the favorite of yuppies or people who tend to have yuppies. Yuppies is fascinated by Ferrari sports cars, Rolex watches, Gucci accessories, Versace fashion...because they believe in the quality and reputation these high-end items represent.

Since the beginning of the 1990s, the economic depression in Europe and the United States has continued to be sluggish. Costumes have returned to the 1970s, and new punk styles have become popular. Avant-garde, changeable, unpredictable and eclectic, it exceeds the usual aesthetic standards and is unruly. But at this time, people's environmental awareness began to increase, and "protecting the human living environment" and "recycling and reusing resources" became a consensus. People began to reflect on excessive consumption, against fashion, against waste of resources, and return to nature. At this time, the main characteristics of the clothing are: Lingerie Look, Hollowing phenomenon, ruggedness, and the reprocessing of classical art styles.

\section{China's contemporary dress etiquette system and economic development}

Nowadays, all countries pay attention to economic development and regard the economy as the primary productive force. Naturally, the development of dress etiquette is mostly affected by economic development, and other factors of influence are placed as second. The stronger the economy, the stronger the dress etiquette is. Today's Chinese clothing is no longer a comparison of vertical development from ancient times to the present, but a horizontal comparison with the world. The trend of apparel development in economically developed countries often leads the world's apparel trend.

The first problem human beings face is food and clothing. After solving food and clothing problem, clothing style will be taken into consideration, and then dress etiquette will be studied to form a specific dress culture. The better the economic foundation, the better 
the development of dress etiquette is. The clothing of some neighboring countries are typical examples. This phenomenon also exists in Chinese economic development. China's vast territory and unbalanced local economic development have also created obvious regional differences. Dress etiquette culture has always kept pace with economic prosperity. In areas with good economic development, their dress culture is also more developed. The openness and differentiation of dress culture are related to the economy, and the economic function has become the root of the development of dress culture. Because the substantial economic foundation enhances the purchasing power of the society, people have more explicit requirements for the functionality, practicality and aesthetic value of clothing, which has also accelerated the development of dress culture.

Dress is a person's appearance, and a barometer of the quality of one's life. Dress reflects a person's spirit, life, and work. The strength of the economy in each era is different, so people's clothing and life which is reflected by economy is also different. The colors, patterns, and styles of the clothes have the economic characteristics of the times. For example, in the early stage of China's reform and opening up, the economic foundation is weak, and it is just at the beginning stage, when the situation reflected in the clothing, that is, the fabric, style, and color are simple and plain, simplicity is regarded as beauty. Today's apparel boldly draws on and absorbs the advanced experience of apparel from Western developed countries, Chinese people's pursuit of dress has turned to individualization and diversification. People no longer simply follow the "popularity" blindly, but choose the clothes they like and suit themselves.

Dress is a reflection of economic foundation and superstructure. China's economic status and technological level are becoming more and more advanced in the world. China's dress will also become stronger, and people's aesthetic level and consumption desire will become higher and higher. China has a history of thousands of years of dress culture, and the glory of the "Golden Tang Dynasty" once led the development of the world economy, the embroidery technology of the Qing Dynasty has also reached the height of perfection. Throughout China's dress history, we have abundant resources, we don't have to blindly follow the development trend of foreign dress, our clothing can also follow China's unique development path like our economy. China should have its own clothing design, which should embody its own cultural characteristics and unique charm, and also embody the unique aesthetic taste and regional culture of the Chinese. With the development of Chinese economy and the enhancement of innovation consciousness, Chinese dress will certainly be able to create greater glories.
In summary, dress etiquette is closely related to social and economic development. If we want to know the development level of certain country in the historical period, we only need to know the clothing and etiquette performance of the people at that time, which will roughly tell us the material development level of that period. The development of China's market economy has driven the development of dress culture, and has been continuously integrated with the world's dress culture. The style of clothing has also changed from every ten years to every three years, and now there are new changes in styles every year. Clothing that was popular last year may be outdated this year, which is also the change brought by economic development.

\section{CONCLUSION}

In short, as an indispensable necessity of daily life, dress will continually change with a new look under the influence of modern social economy, politics, culture and ideas. Contemporary dress is developing in several directions such as diversification, humanization, and refinement, and a brand-new dress art is being formed. It is foreseeable that this art will eventually evolve into the contemporary dress etiquette culture and pass down to next generations.

\section{References}

[1] Gu Xijia. Etiquette and Chinese Culture [M]. Beijing: People's Publishing Company, 2001. (in Chinese)

[2] Zhang Zihui. The Value and Reflection of Etiquette Culture [M]. Shanghai: Xuelin Press, 2008. (in Chinese)

[3] Jiang Jingping. Ethical Perspective of Etiquette [M]. Beijing: China Social Sciences Press, 2007. (in Chinese)

[4] Liu Guolian. History of Chinese and Foreign Clothing [M] Shanghai: East China University Press, 2004. (in Chinese)

[5] Guan Jie. Personal Image Design [M]. Beijing: China Drama Press, 2008. (in Chinese)

[6] Hua Mei. History of Chinese Clothing [M]. Tianjin: People's Fine Arts Publishing House, 1999. (in Chinese) 